ORIGINAL ARTICLE

\title{
Biomonitoring of a worker population exposed to platinum dust in a catalyst production plant
}

\author{
F Petrucci, N Violante, O Senofonte, A Cristaudo, M Di Gregorio, G Forte, A Alimonti
}

Occup Environ Med 2005;62:27-33. doi: 10.1136/oem.2004.016022

See end of article for authors' affiliations ......................

Correspondence to: Dr F Petrucci, Istituto Superiore di Sanità, Department of

Environment and Primary Prevention, Viale Regina Elena 299, 00161 Roma, Italy; francesco.petrucci@ iss.it

Accepted

5 September 2004

\begin{abstract}
Aims: To evaluate the occupational exposure to platinum in an industrial plant engaged in the production, recovery, and recycling of catalytic converters for the automotive traction and chemical industries.

Methods: Pt was determined in airborne particulate matter, and blood, urine, and hair of 106 exposed workers, 21 controls from the plant's administrative offices, and 25 unexposed subjects.

Results: The highest air Pt level was found in the department of the plant in which supports are coated with acid metal solutions, where values of 2.39 and $4.83 \mu \mathrm{g} / \mathrm{m}^{3}$ respectively were found in environmental airborne particulate matter and in air collected using personal sampler devices. The percentage of soluble $\mathrm{Pt}$ was also highest in this area, varying from $24 \%$ to $44 \%$ of the total. The biological data confirmed this trend, with mean concentrations in this site being higher than in other working areas: $1.86 \mu \mathrm{g} / \mathrm{l}$ (urine), $0.38 \mu \mathrm{g} / \mathrm{l}$ (blood), and $2.26 \mu \mathrm{g} / \mathrm{kg}$ (hair). The workers employed in the administrative sector, who were not directly exposed to Pt, had levels of contaminant lower than those of other workers, albeit 2-20 times higher than those of external controls. High correlations were obtained between $\mathrm{Pt}$ levels detected in airborne samples using personal devices and those found in urine and hair, but not in blood.

Conclusions: The background level of $\mathrm{Pt}$ in all areas of the factory implies widespread exposure for the workers. The most reliable biomarker was urine. Hair cannot be considered a good index of time related exposure, at least until more reliable methods of washing can be found that are able to remove exogenous Pt completely.
\end{abstract}

$\mathrm{R}$ eports of health problems associated with exposure to $\mathrm{Pt}$ and related salts date back to the early twentieth century. ${ }^{12}$ Airborne Pt concentrations at platinum refineries have been measured since 1945 and associated with the risk of allergic airways reactions. In 1990, Baker and colleagues ${ }^{3}$ conducted a cross-sectional medical investigation to determine the sensitisation to Pt salts of workers employed in a precious metals refinery, and Maynard and colleagues ${ }^{4}$ examined some cases of respiratory sensitisation to soluble $\mathrm{Pt}$ arising from a Pt group elements (PGEs) industry. Many studies on animals have confirmed the association of acute toxic effects with the metal form, while soluble compounds are much more toxic. For instance, ammonium tetrachloroplatinate has been reported to induce acute poisoning in rats, with hypokinesia, diarrhoea, convulsions, and respiratory impairment, while hexachloroplatinic acid was found to be highly nephrotoxic. ${ }^{56}$ This latter side effect is also well documented in anticancer chemotherapy using complex halide Pt salts, such as cisplatin and its analogues. The adverse health effects of the Pt halide salt complexes associated with occupational exposure are characterised essentially by sensitisation. Biomonitoring of this metal in human fluids is recommended to evaluate individual $\mathrm{Pt}$ exposure and to prevent allergenic effects of Pt salts in catalyst production plants. ${ }^{7}$ Schierl et al found that urine Pt excretion in industry workers after a shift was 1000 times above the mean value of unexposed subjects, with a maximum 10 hours after inhalation. ${ }^{8}$ This study evaluates the occupational exposure in an industrial plant involved in the production and recycling of catalytic converters for the automotive traction and chemical industries. It also assesses the most reliable biomarker for this kind of exposure. To do this we measured: (1) Pt in the $\mathrm{PM}_{10}$ fraction of airborne dust; (2) total Pt and its soluble chemical species in whole airborne dust; and (3) Pt in biological samples taken from workers.

\section{METHODS}

\section{Plant departments and production processes}

All plant departments and production processes were considered in the study, for which samples of airborne particulate matter were collected by means of either area or individual samplers. Two departments are involved in metal dissolution, namely SSD1 and SSD2, where the metallic elements are treated with acids, precipitated, and dissolved in inorganic and organic additives. These departments comprise a dissolution area, where the Pt powder or sponge ( $\mathrm{Pt}$ in metallic form as $99.99 \% \mathrm{Pt}$ ) is dissolved in acid solutions, and a hydrolysis and precipitation area, where $\mathrm{Pt}, \mathrm{Pd}$, and Rh salt solutions (hexachloroplatinic and hexahydroxyplatinic acids, $\mathrm{Rh}$ chloride and nitrate, Pd nitrate, etc) at $10-25 \%$ are produced.

Slurry or fixed bed PGE catalysts for the chemical, petrochemical, and pharmaceutical industries are prepared in the process catalyst department, where the acid metal solutions are absorbed on the carrier (alumina powder pellets and carbon powder or spheres). The operations are performed at room temperature and in a heated environment. Metal is present in the final solid product at concentrations varying from $0.5 \%$ to $10 \%$.

Environmental catalyst devices such as household appliances and catalytic converters for motorcycles and power motors are manufactured in the coating department. Here the ceramic or metallic honeycomb or other special supports are coated by dispersing acid metal solutions. The metal used is essentially Pt (ca. 70\%), but Pd and Rh are also used. This department comprises six areas: (1) the slurry preparation site (mills), where solutions are mixed with the powder while being stirred; (2) the manual spraying area (washcoat), where catalysts are manually coated with PGE solutions; (3)

Abbreviations: PGE, platinum group element; PM, particulate matter 
an area (production) in which supports are automatically or semi-automatically impregnated by immersion; (4) the section containing the ovens, in which catalysts are dried; (5) the catalyst cleaning area; and (6) the packing section.

In the recycling service PGEs are recovered from the spent catalysts, which are first burnt in furnaces or incinerators (oven area). The ashes containing PGEs are thoroughly sieved (sampling area) before being sent to the refinery department, where the PGEs are obtained in metallic form by leaching with strong acid solutions.

All processing departments are equipped with hoods and extraction vents with reactors with vacuum and cartridge filters. Personal protection disposable coveralls, gloves, goggles, and respiratory protective equipment were worn by workers involved in some operations such as coating of catalyst supports, absorption of Pt solutions on the carrier, ashes manipulation, etc, but not by subjects in the immediate area.

An analytical laboratory handles the quality control for all production processes involving raw materials and intermediate and finished products. The remaining areas are not involved in the production processes and include the administration offices, canteen, reception area/porter's lodge, etc.

\section{Selection of subjects}

One hundred and twenty two subjects (101 males, 21 females) aged between 21 and 61 years (mean 36.5 years, median 34 years) were selected. Eighty four subjects, employed in the production sectors, were classified as exposed, 17 subjects employed in the quality control were considered occasionally exposed. As an internal control group, 21 workers employed in the remaining areas, and therefore not directly exposed, were also monitored. The 84 exposed subjects were divided as follows: SSD1, 14; SSD2, 8; coating dept, 26; process catalyst dept, 14; recycling service, 14; and refinery dept, 8 . Among the 122 selected subjects, 22 workers representing all departments were asked to wear personal air samplers. In addition, 25 unexposed subjects living in a rural area were enrolled in the study as external controls.

Personal data and information on specific job typology, state of health, dietary habits, consumption of pharmaceutical drugs, alcohol, coffee, or tobacco, and the presence of dental prostheses were collected by asking the subject to complete a form.

The planned study was approved by the Ethics Committee of the Istituto Superiore di Sanità of Rome and by Istituto Dermatologico San Gallicano of Rome. All subjects gave their informed consent after the objectives of the investigation had been illustrated.

\section{Sample collection and storage}

\section{Airborne particulate matter}

To evaluate exposure to breathable $\mathrm{Pt}$, samples of airborne particles with diameter $<10 \mu \mathrm{m}$ were collected, using pumps (Bravo, Tecora, Milan, Italy) equipped with a $\mathrm{PM}_{10}$ sampling head with cellulose ester filters $(0.8 \mu \mathrm{m}$ pore size, $47 \mathrm{~mm}$ diameter) and a flow rate of $17 \mathrm{l} / \mathrm{min}$. Because the Pt soluble fractions appear more closely correlated with the onset of clinical symptoms, the presence of soluble Pt species in the working environment was evaluated by extracting them from the whole airborne dust sampled at a flow rate of $25 \mathrm{l} / \mathrm{min}$ without the $\mathrm{PM}_{10}$ sampling heads. To avoid clogging of the filters, the latter sampling was performed only during the actual working time-that is, for intervals of 13-57 hours. In addition, to evaluate individual exposure, airborne particulate matter was also collected by personal sampler devices

Table 1 Collection conditions for airborne particulate matter

\begin{tabular}{|c|c|c|c|c|c|}
\hline \multirow[b]{2}{*}{ Site } & \multirow[b]{2}{*}{ Type of process } & \multicolumn{2}{|c|}{ Environmental samplers } & \multicolumn{2}{|l|}{ Personal samplers } \\
\hline & & $\begin{array}{l}\mathrm{PM}_{10^{*}} \\
\text { (air volume in } \mathrm{m}^{3} \text { ) }\end{array}$ & $\begin{array}{l}\text { Whole airborne* } \\
\text { (air volume in } \mathrm{m}^{3} \text { ) }\end{array}$ & $\begin{array}{l}\text { Whole airborne* } \\
\text { (air volume in } \mathrm{m}^{3} \text { ) }\end{array}$ & Days/week \\
\hline SSD1 & Dissolution and hydrolysis & $100(120)$ & NS & $2.4(20) \dagger$ & 3 \\
\hline SSD2 & Dissolution & $43(36) \dagger$ & $30(20)$ & $3.1(26) \ddagger$ & 5 \\
\hline SSD2 & Hydrolysis & $77(72) \dagger$ & 27 (18) & $3.3(27.5) \ddagger$ & 5 \\
\hline$C D$ & Washcoat 1 & $92(96)$ & $52(35)$ & $2.7(23)$ & 5 \\
\hline$C D$ & Washcoat 2 & 107 (120) & NS & $3.2(27)$ & 5 \\
\hline$C D$ & Washcoat 3 & NS & NS & $3.2(27)$ & 5 \\
\hline$C D$ & Washcoat 4 & NS & NS & $3.2(27)$ & 5 \\
\hline$C D$ & Ovens 1 & $110(120)$ & $57(38)$ & NS & NS \\
\hline$C D$ & Ovens 2 & $111(120)$ & NS & NS & NS \\
\hline$C D$ & Mills & $104(120)$ & NS & $2.6(22)$ & 5 \\
\hline$C D$ & Packing & $101(120)$ & $86(57)$ & NS & NS \\
\hline$C D$ & Production 1 & 97 (120) & 59 (39) & $2.9(24)$ & 5 \\
\hline$C D$ & Production 2 & NS & NS & $3.1(26)$ & 5 \\
\hline$C D$ & Catalyst cleaning & $99(120)$ & NS & NS & NS \\
\hline PCD & Carbon coating 1 & $109(120)$ & $32(21)$ & $2.6(22)$ & 5 \\
\hline PCD & Carbon coating 2 & $113(120)$ & 55 (37) & $2.6(22)$ & 5 \\
\hline PCD & Carbon coating 3 & NS & NS & $2.6(22)$ & 5 \\
\hline PCD & Packing 1 & $105(120)$ & $16(13)$ & $2.0(16)$ & 5 \\
\hline PCD & Packing 2 & $117(120)$ & NS & $3.0(25)$ & 5 \\
\hline RS & Ovens & $69(72) \dagger$ & $73(49)$ & $1.9(13)$ & 5 \\
\hline RS & Sampling & $78(72) \dagger$ & $46(31)$ & $2.6(21)$ & 5 \\
\hline RD & Ash leaching 1 & $87(96)$ & $67(45)$ & $3.8(32)$ & 5 \\
\hline RD & Ash leaching 2 & $93(96)$ & NS & $3.1(26)$ & 5 \\
\hline $\mathrm{AL}$ & Quality control & NS & $35(23)$ & NS & NS \\
\hline AS & Administration 1 & $123(120)$ & $76(51)$ & $3.5(29)$ & 5 \\
\hline AS & Administration 2 & 55 (48) & NS & NS & NS \\
\hline EC & Non-exposed area & $89(96)$ & NS & NS & NS \\
\hline \multicolumn{6}{|c|}{$\begin{array}{l}\text { NS, not sampled; SSD, metal dissolution depa } \\
\text { laboratory; AS, remaining areas; EC, external } \\
\text { *Sampling duration in hours in parentheses. } \\
\text { †Work shift collection. } \\
\text { †Mean of two samplings. }\end{array}$} \\
\hline
\end{tabular}


Table 2 Concentrations $\left(\mu \mathrm{g} / \mathrm{m}^{3}\right)$ of $\mathrm{Pt}$ in $\mathrm{PM}_{10}$ airborne samples, total and soluble $\mathrm{Pt}$ in airborne samples, and whole total airborne matter collected with personal samplers

\begin{tabular}{|c|c|c|c|c|c|c|}
\hline \multirow[b]{3}{*}{ Site } & \multirow[b]{3}{*}{ Type of process } & \multicolumn{4}{|c|}{ Environmental samplers } & \multirow{3}{*}{$\begin{array}{l}\text { Personal samplers } \\
\text { Whole airborne }\end{array}$} \\
\hline & & \multirow[b]{2}{*}{$\mathrm{PM}_{10}$ airborne } & \multicolumn{3}{|c|}{ Whole airborne samples } & \\
\hline & & & Total Pt & Soluble Pt & Soluble/total (\%) & \\
\hline SSDI & Dissolution and hydrolysis & 0.01 & - & - & - & 0.32 \\
\hline SSD2 & Dissolution & 0.02 & 0.06 & 0.02 & 34.1 & 0.47 \\
\hline SSD2 & Hydrolysis & 0.04 & 0.11 & 0.02 & 15.1 & 0.43 \\
\hline Mean & & 0.02 & 0.08 & 0.02 & 24.6 & 0.41 \\
\hline$C D$ & Washcoat 1 & 1.70 & 0.60 & 0.21 & 35.0 & 2.97 \\
\hline$C D$ & Washcoat 2 & 0.65 & - & - & - & 0.97 \\
\hline$C D$ & Washcoat 3 & - & - & - & - & 1.26 \\
\hline$C D$ & Washcoat 4 & - & - & - & - & 1.70 \\
\hline$C D$ & Ovens 1 & 0.79 & 0.96 & 0.29 & 30.2 & - \\
\hline$C D$ & Ovens 2 & 0.87 & - & - & - & - \\
\hline$C D$ & Mills & 1.25 & - & - & - & 2.55 \\
\hline$C D$ & Packing & 1.84 & - & - & - & - \\
\hline$C D$ & Production 1 & 2.40 & 6.06 & 1.51 & 24.9 & 4.83 \\
\hline$C D$ & Production 2 & - & - & - & - & 4.46 \\
\hline$C D$ & Catalyst cleaning & 0.136 & - & - & - & - \\
\hline Mean & & 1.21 & 2.54 & 0.67 & 30.1 & 2.70 \\
\hline PCD & Carbon coating 1 & 0.24 & 0.74 & 0.04 & 6.00 & 0.13 \\
\hline PCD & Carbon coating 2 & 0.13 & - & - & - & 0.06 \\
\hline PCD & Carbon coating 3 & - & - & - & - & 0.02 \\
\hline PCD & Packing 1 & 0.07 & 0.11 & 0.01 & 10.2 & 0.01 \\
\hline PCD & Packing 2 & 0.27 & - & - & - & 0.01 \\
\hline Mean & & 0.18 & 0.42 & 0.03 & 8.00 & 0.05 \\
\hline RS & Ovens & 0.18 & 0.42 & 0.004 & 0.80 & 0.78 \\
\hline RS & Sampling & 0.30 & 0.26 & 0.01 & 4.50 & 0.58 \\
\hline Mean & & 0.24 & 0.34 & 0.08 & 2.65 & 0.68 \\
\hline RD & Ash leaching 1 & 0.03 & - & - & - & - \\
\hline RD & Ash leaching 2 & 0.01 & - & - & - & 0.06 \\
\hline Mean & & 0.02 & - & - & - & 0.06 \\
\hline $\mathrm{AL}$ & Quality control & - & 0.02 & 0.01 & 42.6 & - \\
\hline AS & Administration 1 & 0.01 & 0.01 & 0.002 & 17.9 & 0.01 \\
\hline AS & Administration 2 & 0.01 & - & - & - & - \\
\hline Mean & & 0.01 & 0.01 & 0.002 & 17.9 & 0.01 \\
\hline EC & Non-exposed area & $<0.00002$ & - & - & - & - \\
\hline
\end{tabular}

$S S D$, metal dissolution department; $C D$, coating dept; $P C D$, process catalysis dept; $R S$, recycling service; $R D$, refinery dept; $A L$, analytical laboratory; $A S$, remaining areas; $\mathrm{EC}$, external control.

worn by individual workers for a whole week. Air samples were collected through cellulose nitrate filters $(0.8 \mu \mathrm{m}$ pore size, $25 \mathrm{~mm}$ diameter) by GilAir-5 pumps (Sensidyne, Clearwater, FL, USA) at a flow rate simulating human breathing-that is, $2.0 \mathrm{l} / \mathrm{min}$. Collection sites and sampling duration were chosen as previously reported (see table 1). Sampling of environmental $\mathrm{PM}_{10}$ airborne particulate matter and of whole airborne particulate matter collected by personal devices was generally performed during the entire working week or, in particular manufacturing cycles, during the work shift. A non-exposed area, far away from the plant, was chosen for external control sampling.

\section{Biological samples}

All biological specimens were collected simultaneously in the morning of the last day of the working week-that is, at the end of five days of exposure. Aliquots of $1 \mathrm{ml}$ of blood were collected in polyethylene tubes (Falcon, Becton Dickinson, Lincoln Park, NJ, USA), while spot urine was sampled in high density polyethylene bottles (Kartell, Milan, Italy) previously washed with a $10 \% \mathrm{HNO}_{3}$ solution. ${ }^{10}{ }^{11}$ Hair was collected from the occipital area at a distance of approximately $\mathrm{l} \mathrm{cm}$ from the scalp by means of titanium nitride coated scissors. Details of sampling procedures have been reported previously. ${ }^{9}$

\section{Sample pretreatment and analysis}

Filters

Cellulose filters were completely digested in a microwave oven in high pressure Teflon vessels (MLS 1200 MEGA, Milestone, Bergamo, Italy) prior to analysis. ${ }^{12}$ When the soluble fraction of $\mathrm{Pt}$ was determined, half the filter was treated according to the Health and Safety Executive method..$^{13}$ In particular, filters were twice placed in $10 \mathrm{ml}$ of $0.07 \mathrm{M} \mathrm{HCl}$ solution in an ultrasonic bath for 30 minute to extract the soluble Pt. The final solution was centrifuged at $4000 \mathrm{rpm}$ for 15 minutes and the supernatant was evaporated in a vacuum in a microwave oven. The final residue was diluted to $5 \mathrm{ml}$ with $0.07 \mathrm{M} \mathrm{HCl}$ solution. In the extraction recovery test, $1 \mathrm{ml}$ of Pt solution at a concentration of $4 \mu \mathrm{g} / \mathrm{l}$ was adsorbed on a filter and subjected to the whole analytical procedure.

\section{Biological samples}

Blood and urine samples were digested in an ETHOS 900MEGA 2 microwave unit (Milestone, Italy) equipped with a Multi-PREP 80 rotor in a temperature controlled programme as previously reported. In the case of hair, a standard washing procedure was carefully performed before the digestion process to remove as much exogenous contamination as possible. 


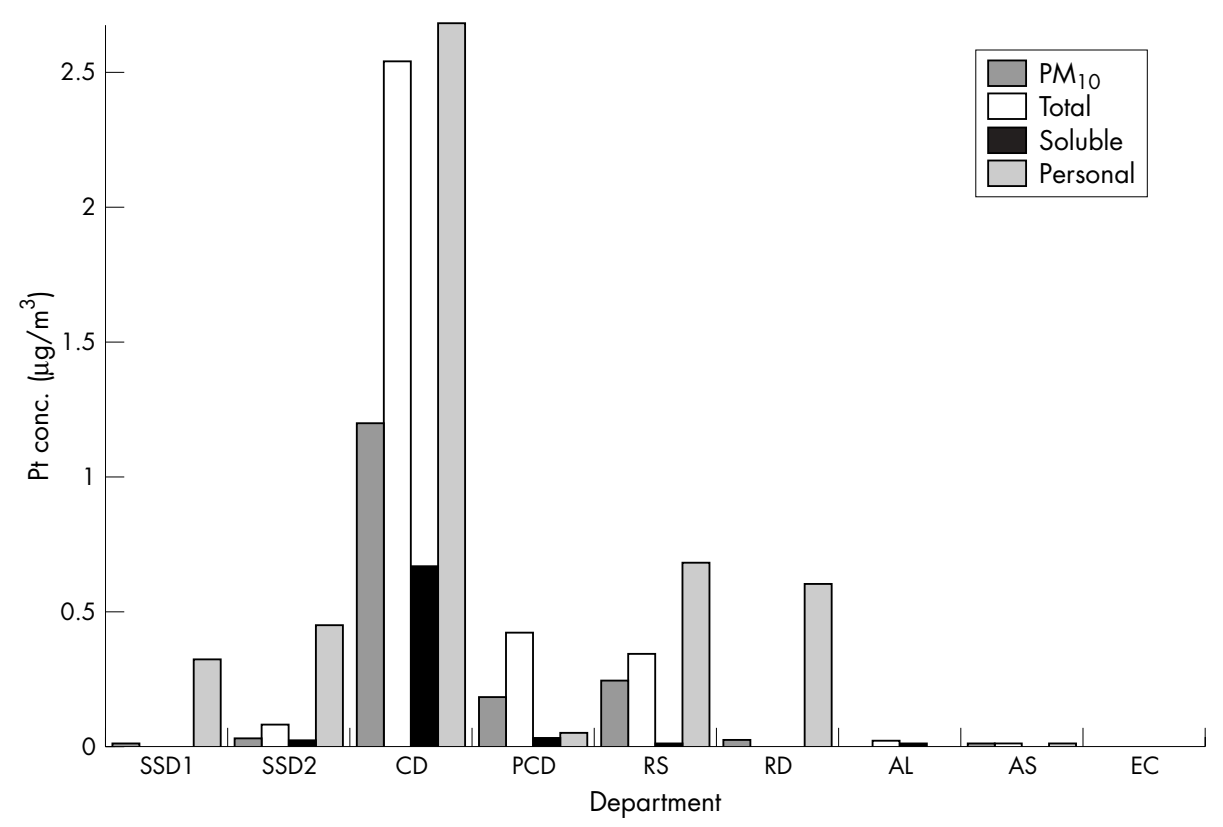

Figure 1 Mean Pt concentrations in plant departments. PM 10 , total and soluble Pt collected by environmental samplers; Personal, Pt in airborne matter collected by personal devices; SSD, metal dissolution department; $C D$, coating dept; PCD, process catalysis dept; RS, recycling service; RD, refinery dept; AL, analytical laboratory; AS, remaining areas; EC, external control.

Quantitative analyses of biological matrices and of the environmental samples were performed by means of HR-ICPMS and Q-ICP-MS. The analytical procedure is reported in detail elsewhere. ${ }^{9}$ Briefly, the performance of the developed method was as follows: (1) for airborne particulate matter, limits of detection were $0.018 \mathrm{ng} / \mathrm{m}^{3}$, repeatability $2 \%$, and recovery 96\%; (2), for all biological samples, limits of detection were $1-3 \mathrm{ng} / \mathrm{l}$, precision $2.7-5.1 \%$, and recovery $94.5-105 \%$.

\section{Statistical evaluation}

The SPSS statistical package (SPSS Inc., Chicago, IL, USA) was used for processing experimental data. Mean, standard deviation (SD), median, and experimental and fractile intervals were calculated. Values more than 1.5 of the interquartile range were eliminated as outliers. The distribution of results was tested for normality using the Kolmogorov-Smirnov test. The correlations between environmental exposure data and biological results, and between the levels of platinum in blood, hair, and urine were evaluated by Pearson's test. A p value $\leqslant 0.05$ was considered significant in all statistical analyses.

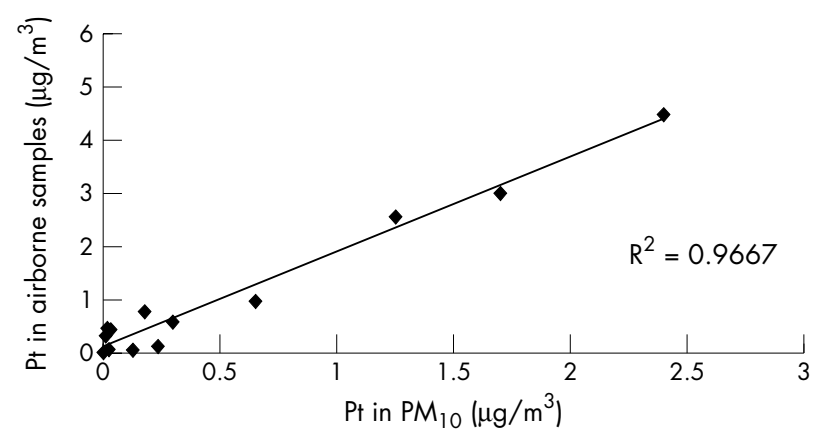

Figure 2 Correlation between $\mathrm{Pt}$ levels in $\mathrm{PM}_{10}$ airborne samples collected using environmental samplers and in airborne matter sampled by means of personal devices.

\section{RESULTS AND DISCUSSION}

\section{Environmental samples}

Table 2 reports the concentrations of $\mathrm{Pt}$ in $\mathrm{PM}_{10}$ airborne particulate matter, the total and soluble Pt levels in the total airborne matter collected from all the plant sites, as well as the Pt levels in airborne matter collected by personal devices. The highest mean level of $\mathrm{Pt}$ in $\mathrm{PM}_{10}$ was found in the coating department (production area), where the Pt salt solutions are used to coat catalytic supports. In the process catalyst site, where Pd is mainly used for catalysis, the levels of Pt were one tenth of those in the coating department. In the SSD1 and SSD2 areas, the content of the metal was lower by two orders of magnitude than in the coating department. An intermediate level of Pt contamination was found in the recycling service, where the element is recovered from exhaust catalysts, while in the refinery department (leaching of ashes) the exposure falls to levels similar to those found in SSD. In the remaining areas, the Pt levels were much lower than those in the processing areas, though still 1000 times higher than those found in external controls sampled far away from the plant.

A similar pattern for Pt was found in whole airborne matter, with the following sequence: coating dept $>$ process catalyst dept $>$ recycling service $>$ SSD $>$ remaining areas. In some cases, namely the coating dept (washcoat 2 and ovens 1 areas) and the recycling service (sampling area), Pt seems to be associated mainly with the fine fraction $<10 \mu \mathrm{m}$, as shown by the similar amounts of $\mathrm{Pt}$ in $\mathrm{PM}_{10}$ and whole airborne matter. In the other areas of the plant about $50 \%$ of Pt was found to be associated with the coarse fraction-that is, particles $>10 \mu \mathrm{m}$. When evaluating the health risk associated with the absorption of Pt through the skin or mucus, it is very important to measure the soluble fraction. The highest percentage of soluble $\mathrm{Pt}$ was found in the department where the Pt solutions are used as coatings (coating dept, mean ca. $30 \%$ of the total). In the recycling department, where Pt is present essentially in a metallic state, the fraction of soluble element fell to $2.65 \%$. In other plant sites, where $\mathrm{Pt}$ pollution values were in the order of 

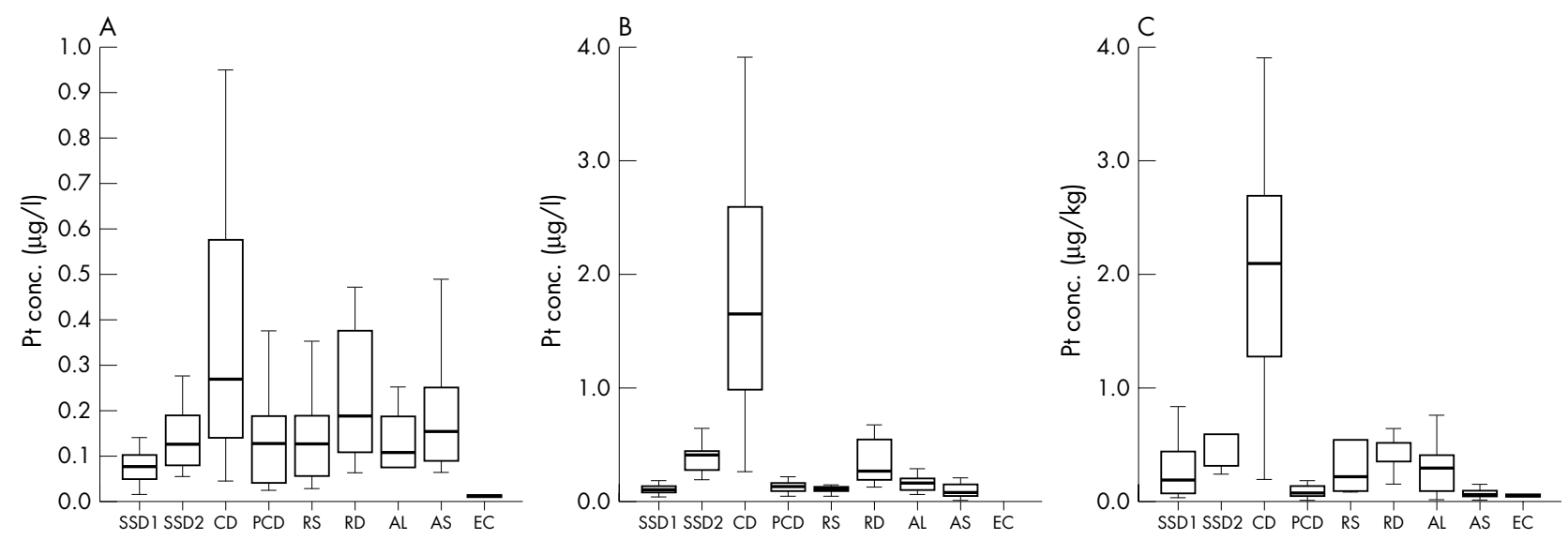

Figure 3 Box and whisker plots of the data relating to the biomonitoring of workers: $(A)$ blood; (B) urine; (C) hair. SSD, metal dissolution department; $C D$, coating dept; $P C D$, process catalysis dept; $R S$, recycling service; $R D$, refinery dept; $A L$, analytical laboratory; $A S$, remaining areas; $E C$, external control.

$0.1 \mu \mathrm{g} / \mathrm{m}^{3}$, as in the coating department and SSD sectors, the soluble/total mean ratios ranged from $8 \%$ to $22 \%$.

The highest concentration of soluble Pt found in the plant was $1.5 \mu \mathrm{g} / \mathrm{m}^{3}$ (production area of the coating department). When normalised as time weighted average threshold limit (eight hour TWA) this data becomes equal to $0.31 \mu \mathrm{g} / \mathrm{m}^{3}$ and is much lower than the threshold limit value (TLV) established by the OSHA $\left(2 \mu \mathrm{g} / \mathrm{m}^{3}\right)$. Pt found in the plant as total inhalable dust was always in the order of $\mu \mathrm{g} / \mathrm{m}^{3}$ while the TWA-TLV is in the order of $\mathrm{mg} / \mathrm{m}^{3}$.

The data relating to individual exposure obtained using the personal samplers display a pattern similar to that of the environmental results, with the highest concentrations $\left(0.97-4.83 \mu \mathrm{g} / \mathrm{m}^{3}\right)$ being found in the coating departmentthat is, the department where a high dispersion of Pt in the air is produced. In the recycling service levels of about $0.68 \mu \mathrm{g} / \mathrm{m}^{3}$ of Pt were measured, while in SSD, where salts are handled, the values found were about $0.41 \mu \mathrm{g} / \mathrm{m}^{3}$. Platinum concentrations below $0.1 \mu \mathrm{g} / \mathrm{m}^{3}$ were found in all the other department areas. Figure 1 gives a summary picture of the exposure levels to Pt inside the factory, while fig 2 shows the very high correlation existing between the $\mathrm{Pt}$ contents in the airborne samples collected using area and personal samplers $\left(\mathrm{r}^{2}=0.9667, \mathrm{p} \leqslant 0.001\right)$.

\section{Biological samples}

Table 3 reports the mean values of Pt in blood, urine, and hair samples collected during the environmental monitoring. Figure 3 shows the same data in terms of median, 25-75\% fractiles, and experimental ranges, in the form of box and whisker plots. The highest mean level of Pt in all matrices was found in the coating department, confirming the picture of environmental exposure. The range between the minimum and maximum values also showed the greatest dispersion of data in this department (see fig 3).

The intervals of concentrations found in blood and urine are in agreement with other similar occupational studies. ${ }^{8}{ }^{14}$ No data on hair as a marker of Pt exposure are reported in the literature. Among the production sectors, the lowest values were found as follows: (1) for blood, in SSD1, SSD2, and the recycling service; (2) for urine, in the process catalyst department, recycling service, and SSDI; and (3) for hair, in the process catalyst department, refinery department, and SSD1. The workers employed in the remaining sectors, although not directly exposed to Pt dust, presented levels of contaminant similar to those found in workers involved in the production processes and 2-20 times higher than the external controls. This fact could be considered a consequence of the increased baseline pollution occurring inside

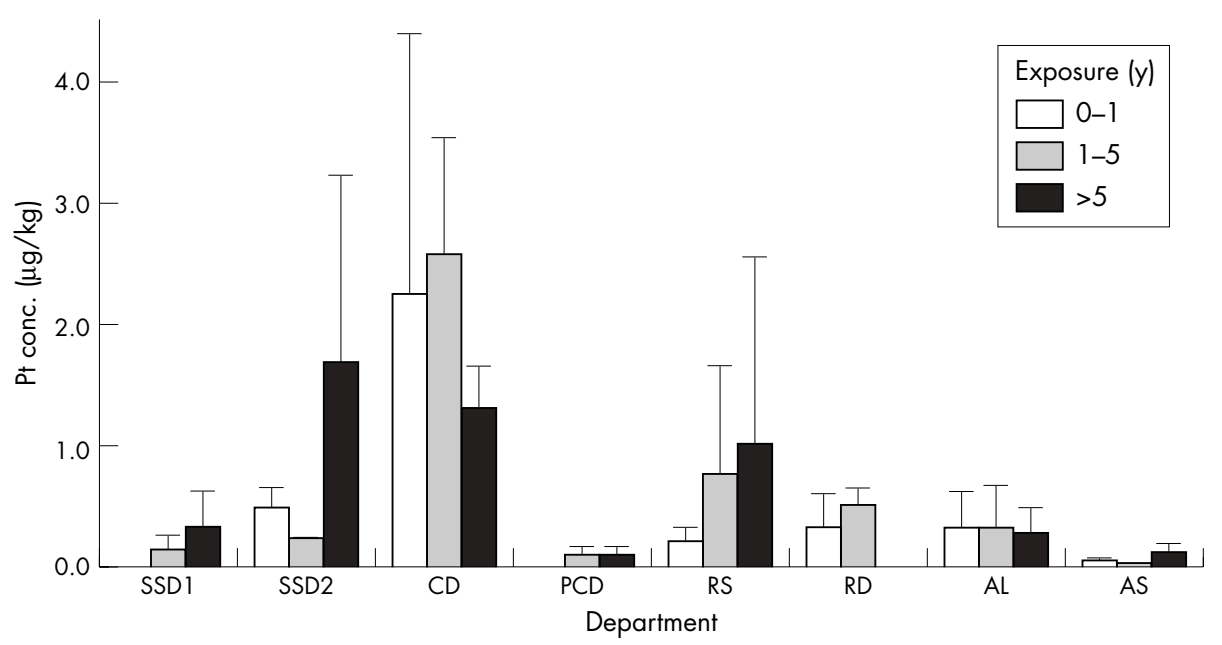

Figure 4 Mean Pt concentrations in hair as a function of the years of employment in each department. SSD, metal dissolution department; CD, coating dept; $P C D$, process catalysis dept; $R S$, recycling service; $R D$, refinery dept; $A L$, analytical laboratory; $A S$, remaining areas. 
Table 3 Mean concentrations of Pt in biological samples from workers

\begin{tabular}{|c|c|c|c|}
\hline Site & Blood ( $\mu \mathrm{g} / \mathrm{l})$ & Urine $(\mu \mathrm{g} / \mathrm{l})$ & Hair mean $(\mu \mathrm{g} / \mathrm{kg})$ \\
\hline SSDI & $0.07(0.04)$ & $0.11(0.04)$ & $0.28(0.28)$ \\
\hline SSD2 & $0.14(0.08)$ & $0.39(0.16)$ & $0.91(1.06)$ \\
\hline$C D$ & $0.38(0.31)$ & $1.86(1.12)$ & $2.26(1.59)$ \\
\hline PCD & $0.17(0.17)$ & $0.14(0.06)$ & $0.10(0.06)$ \\
\hline RS & $0.14(0.11)$ & $0.17(0.20)$ & $0.84(1.18)$ \\
\hline RD & $0.24(0.17)$ & $0.36(0.22)$ & $0.24(0.19)$ \\
\hline$A L$ & $0.13(0.06)$ & $0.17(0.10)$ & $0.31(0.24)$ \\
\hline AS & $0.18(0.12)$ & $0.10(0.06)$ & $0.08(0.06)$ \\
\hline Controls & $0.01(0.002)$ & $0.005(0.0001)$ & $0.05(0.008)$ \\
\hline Literature & $0.3-1.8^{*}$ & $0.33-5.3+$ & $\ddagger$ \\
\hline \multicolumn{4}{|c|}{$\begin{array}{l}\text { Results expressed as mean (SD). } \\
\text { SSD, metal dissolution department; } C D \text {, coating dept; } P C D \text {, process catalysis dept; RS, recycling service; RD, } \\
\text { refinery dept; } A L \text {, analytical laboratory; } A S \text {, remaining areas; } E C \text {, external control. } \\
\text { *From reference } 14 \text {; ffrom reference } 8 \text {; łno literature data available. }\end{array}$} \\
\hline
\end{tabular}

the factory. In fact, outdoor collections of $\mathrm{PM}_{10}$ performed inside the factory area gave very homogeneous results, with a mean equal to $0.03 \mu \mathrm{g} / \mathrm{m}^{3}$ - that is, three orders of magnitude higher than those found in urban air in the same period. ${ }^{12}$ This widespread air contamination in all plant departments made it impossible to distinguish the portion of the Pt body burden due to the presence of dental prostheses or amalgams-that is, there was no statistical difference between workers with and without noble metal dental interventions/restorations, as was the case, for example, in groups of policemen heavily exposed to a polluted urban atmosphere. ${ }^{10}$

Interestingly, the difference between the lowest $(0.07 \mu \mathrm{g} / \mathrm{l})$ and the highest $(0.38 \mu \mathrm{g} / \mathrm{l})$ mean values found in blood was only $0.31 \mu \mathrm{g} / \mathrm{l}$. This fact, together with the uniform Pt blood distribution among the workers, could be considered to be clear evidence of homogeneous long term exposure to the metal. On the other hand, the high variability of the mean data for hair and urine, as a function of the work site, makes these matrices more responsive as markers of exposure to this metal.

Pearson correlation tests carried out on all the subjects showed statistically significant $(p \leqslant 0.0001)$ associations between urine and hair, and between urine and blood ( $\sigma=0.697$ and $\sigma=0.573$, respectively), while blood and hair were poorly correlated $(\sigma=0.305$, at $\mathrm{p} \leqslant 0.05)$. This scarce correlation between blood and hair and the less significant blood-urine association suggest that blood on the one hand, and hair and urine on the other play different roles in biomonitoring exposure. In particular, the Pt blood level probably represents the body burden of the element most affected by homeostatic processes and is thus less able to provide information on the current degree of exposure (see fig $3 \mathrm{~A}$ ). With regard to urine, excretion of $\mathrm{Pt}$ is known to be a reliable marker of short term exposure, with a maximum being reached nearly 10 hours after inhalation and a half-life of about 50 hours. ${ }^{8}$ Hair tissue in turn is a site of storage for several metals. ${ }^{15-17}$ The correlation found in this study between levels of Pt in hair and in urine may surprisingly point to hair as a marker that is highly reactive to different levels of exposure. This confusing behaviour is probably due to the occurrence of large amounts of exogenous metal absorbed on the outer surface of hair, which is difficult to remove by washing. Thus, the external contamination of hair hides the endogenous Pt content and does not allow the use of this tissue as a marker of long term exposure. It can be seen from fig 4 that the Pt levels in hair are much less affected by the duration of the exposure-that is, by the number of years spent in the same plant site, particularly in cases where the pollution is very high, as in the coating department areas. In conditions of heavy exposure, hair tissue keeps the Pt dust on its surface like an environmental filter, as is also corroborated by the very high association between Pt hair levels and the Pt concentrations in airborne matter collected by means of personal devices from the same subjects $(\sigma=0.917$, at $p \leqslant 0.01)$. A similar association is found when the individual exposures are compared with urine Pt levels $(\sigma=0.918$, at $p \leqslant 0.01)$, but no association is apparent when they are matched against Pt blood concentrations.

\section{Conclusions}

Both environmental and individual monitoring showed that the most heavily contaminated area is the coating department, where the concomitant highest percentage of soluble Pt (up to $44 \%$ of the total) poses some risk for workers' health. However, levels of Pt found in the departments not involved in the industrial processes are lower than those obtained in other factory sites, though still much higher than those found in distant control areas. The biomonitoring data confirm this pattern of exposure, with the Pt body burden for all workers, including those not directly involved in the production processes, being consistently higher than those in the external control subjects. In particular, the mean urine Pt level found in the coating department workers is up to 15 times higher than the Pt excretion of subjects working in other production areas, while Pt blood levels relating to the coating department are only five times higher, thus proving that Pt blood measurements are less able to distinguish exposures of differing seriousness.

On the basis of the above considerations and of the associations between biological and environmental monitoring data, the following conclusions can be drawn: (1) blood is not a suitable biological marker for occupational exposure to Pt; (2) urine could be considered as an efficient biomarker for occupational monitoring; and (3) hair cannot be considered a good indicator of time related exposure, at least until washing methods are found that are able to remove exogenous Pt completely.

\section{Authors' affiliations}

F Petrucci, N Violante, O Senofonte, M Di Gregorio, G Forte,

A Alimonti, Istituto Superiore di Sanità, Laboratorio di Tossicologia Applicata, Rome, Italy

A Cristaudo, Istituto Dermatologico S. Gallicano, Rome, Italy

\section{REFERENCES}

1 Karasek SR, Karasek M, Reprint III. State Commission on Occupational Diseases. Chicago, IL: Warner, 1911:97.

2 Carozzi L. Occupation and health. Geneve 1934;2:669. 
3 Baker DB, Gann PH, Brooks SM, et al. Cross-sectional study of platinum salts sensitization among precious metals refinery workers. Am J Ind Med 1990;18:653-64.

4 Maynard AD, Northage $C$, Hemingway $M$, et al. Measurement of short-term exposure to airborne soluble platinum in the platinum industry. Ann Occup Hyg 1997;41:77-94.

5 Degussa AG. Ammoniumtetrachloroplatinate (II)-acute toxicity after single oral administration in rat. Unpublished report no. 863886. Hanau: Degussa AG, 1989.

6 Ward JM, Joung DM, Fauvie KA, et al. Comparative nephrotoxicity of platinum cancer therapeutic agents. Cancer Treat Rep 1976;60:1675-8.

7 Merget R, Kulzer R, Dierkes-Globisch, et al. Exposure-effect relationship of platinum salt allergy in a catalyst production plant: conclusions from a 5-year prospective cohort study. J Allergy Clin Immunol 2000;105:364-70.

8 Schierl R, Fries H-G, van de Weyer C, et al. Urinary excretion of platinum from platinum industry workers. Occup Environ Med 1998;55:138-40.

9 Petrucci F, Violante N, Senofonte O, et al. Development of an analytical method for monitoring worker populations exposed to platinum-group elements. Microchem J 2004;76:131-4.

10 lavicoli I, Bocca B, Petrucci F, et al. Biomonitoring of traffic police officers exposed to airborne platinum. Occup Environ Med 2004;61:636-9.
11 Bocca B, Alimonti A, Cristaudo A, et al. Monitoring of the exposure to platinum-group elements for two Italian populations. Anal Chim Acta 2004;512:19-25.

12 Petrucci $\mathrm{F}$, Bocca B, Alimonti A, et al. Determination of $\mathrm{Pt} \mathrm{Pd}$, $\mathrm{Pt}$ and $\mathrm{Rh}$ in airborne particulate and road dust by HR-ICP-MS: evaluation of the automotive catalyst emissions in the urban area of Rome. J Anal Atom Spetrosc 2000;15:525-8.

13 Health \& Safety Executive. Platinum metal and soluble platinum compounds in air, MDHS series. London: Health \& Safety Executive Books, 1996: 1-12.

14 Nygren O, Vaughan GT, Florence TM, et al. Determination of platinum in blood by adsorptive voltammetry. Anal Chem 1990;62:1637-40.

15 Schuhmacher M, Belles M, Rico A, et al. Impact of reduction of lead in gasoline on the blood and hair lead levels in the population of Terragona Province, Spain 1990-1995. Sci Total Environ 1996;184:203-9.

16 Batista J, Schuhmacher M, Domingo JL, et al. Mercury in hair for child population from Terragona Province. Spain Sci Total Environ 1996;193:143-8

17 Michael W, Müller F, Idel H. Biological monitoring of mercury vapour exposure by scalp hair analysis in comparison to blood and urine. Toxicol Lett 1996;88:221-6.

\section{$\mathrm{ECHO}$}

Research finds new inequity at work between the sexes

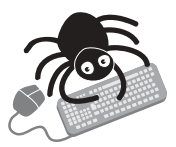

Please visit the Occupational and

Environmental Medicine website [www. occenvmed. com] for a link to the full text of this article.
A study of European Union (EU) workers has suggested that legislation may need to be changed to ensure equity at work because male and female permanent and temporary workers differ in reacting to job stresses-psychosocial work factors-by going sick. This is the first study to explore a link between employment state and-specifically-work related sickness absence and sex, and it underlines the influence of low job control.

Men and women in temporary jobs with low control had much higher risks of sickness absence (adjusted rate ratio 1.63, 1.70, respectively) compared with men and women in permanent jobs with high control as the reference category. In temporary jobs with high control they seemed to have a lesser risk $(0.37,0.94$, respectively). Women in temporary jobs with high job demands had a higher risk of sickness absence (1.28) but less risk (0.69) in temporary, low demand jobs, compared with those in permanent jobs with low demands. Interaction between job stresses and employment state was significant only for control in men and demand in women.

The cross sectional survey-the Third European Survey on Working Conditions (ESWC)comprised data obtained by interview during Mar-April 2000 from a random sample of the total active working population aged $\geqslant 15$ across 15 EU countries. In all, 12875 permanent and 1203 temporary employees contributed.

Work related sickness absence is an important marker of health and productivity of the working population. This study indicates that future research should assess permanent and temporary workers separately.

A Gimeno D, et al. Journal of Epidemiology and Community Health 2004;58:862-869. 